\title{
Improving Safety of Glucose Control in Intensive Care using Virtual Patients and Simulated Clinical Trials
}

\author{
Liam M. Fisk ${ }^{1}$, B.Eng; Aaron J. Le Compte ${ }^{1}$, PhD; Geoffrey M. Shaw ${ }^{2}$ MBChB; \\ J. Geoffrey Chase ${ }^{1^{*}}$, PhD \\ ${ }^{1}$ Department of Mechanical Engineering, Centre for Bio-Engineering, University of \\ Canterbury, Christchurch, New Zealand \\ ${ }^{2}$ Department of Intensive Care, Christchurch Hospital, Christchurch School of \\ Medicine, University of Otago, Christchurch, New Zealand
}

Submitted November 2011. Accepted for publication April 2012.

\begin{abstract}
Despite the potential clinical benefits of normalizing blood glucose in critically ill patients, the risk of hypoglycemia is a major barrier to widespread clinical adoption of accurate glycemic control. To compare five glucose control protocols, a validated insulin-glucose system model was employed to perform simulated clinical trials. STAR, SPRINT, UNC, Yale and Glucontrol protocols were assessed over a medical-surgical intensive care unit patient cohort. Results were interpreted separately for patients with low to high sensitivity to insulin, and low to high variability in metabolic state. STAR and SPRINT provided good glucose control with risk of severe hypoglycemia less than $0.05 \%$ across all patient groups. UNC also achieved good control for patients with low and medium levels of insulin sensitivity (SI), but risk of severe hypoglycemia was raised for patients with high SI. Glucontrol showed degradation of performance for patients with high metabolic variability.
\end{abstract}

Keywords: critical care, glycemic control, virtual trials

\section{INTRODUCTION}

Stress-induced hyperglycemia (high blood sugar levels) affects $30-50 \%$ of intensive care patients [1]. Treatment to normalize blood glucose (BG) concentration with conventional insulin dosing schemes has proved difficult without excessive risk of hypoglycemia [2]. Extreme BG and glycemic variability have been independently linked to increased morbidity and mortality [1,3-5]. Protocols that have successfully

*Corresponding author: J. Geoffrey Chase, Dept. of Mechanical Engineering, University of Canterbury, New Zealand. Phone: +64 21342 743. E-mail: Geoff.chase@canterbury.ac.nz Other authors: liam.fisk@pg. canterbury.ac.nz, aaron.lecompte@canterbury.ac.nz,geoff.shaw@cdhb.govt.nz 
managed BG to within normal ranges have been shown to reduce ICU mortality by $18-45 \%$ [6-8], resulted in faster resolution of organ failure [9], and reduced overall healthcare costs $[10,11]$. However, despite these potential benefits, the risk of hypoglycemia and worsened outcome $[2,12]$ is seen as a major barrier to widespread adoption of accurate glycemic control, with higher BG preferred due to reduced risk of iatrogenic hypoglycemia [13].

Management of BG in intensive care patients presents a significant challenge. Insulin is a potent regulator of carbohydrate metabolism and is routinely administered to combat hyperglycemia. However, a patient's glycemic response to insulin can vary rapidly as a consequence of the initial physiological insult and evolution of condition over time, and predicting such changes in response can be challenging [14]. Medical ICUs typically house a heterogeneous patient population, and control systems that initially work well on a homogenous population can exhibit poorer performance when applied to a broader group of patients $[15,16]$.

In general, ICU patients are less sensitive to insulin than healthy adults, and their insulin sensitivity (SI) varies over time. Only one study [7] has demonstrated both reduction in the incidence of hypoglycemia and improved patient outcomes, with BG controlled effectively by tracking the patient-specific insulin sensitivity, as well as adjusting insulin and nutrition administration [17]. Moreover, the pharmaco-dynamic effect of insulin on the rate of glucose uptake can saturate at high doses [18], suggesting that an account of carbohydrate load may also be an important component of glycemic control [19].

Accurate glycemic control requires balancing insulin and nutrition inputs within clinical guidelines, while also managing changes in patient-specific response to insulin over time. More aggressive insulin dosing can reduce hyperglycemia faster, but increases the risk of hypoglycemia if the patient's insulin sensitivity were to increase suddenly [20]. Responding too slowly or ignoring changes in patient state can allow variability in insulin response to flow through to increase variability in patient's BG levels [17]. Finally, BG measurement devices, especially those used at the point of care, may be prone to inaccuracy and interference, where the response to a falsely high BG measurement may result in clinically significant iatrogenic hypoglycemia [21].

Glucose control protocols in current clinical practice, or used in research studies, range in complexity from (1) simple tables of insulin dosages prescribed in response to current BG levels (e.g., UNC [22], Yale [23], Glucontrol [24]), (2) paper-based adaptive protocols that manage both insulin and carbohydrate inputs [7], to (3) full computerized model-based control systems with glucose prediction capabilities [25, 26]. Metrics describing the behavior of glycemic control protocols vary between studies, making direct comparison difficult, with performance often simply measured by the degree of hypoglycemia and/or mean BG.

A number of protocols have been trialed clinically with varying levels of success. The UNC protocol [22] achieved 36-47\% of BG measurements within the target $70-110 \mathrm{mg} / \mathrm{dL}$ range, with $2.0-2.4 \% \mathrm{BG}<70 \mathrm{mg} / \mathrm{dL}$. Yale protocols have undergone several revisions with different target ranges, where the 2005 version [23] achieved $60 \%$ within the target $90-119 \mathrm{mg} / \mathrm{dL}$ range once glycemia had crossed the $119 \mathrm{mg} / \mathrm{dL}$ 
threshold. The Glucontrol study [24] was a multi-center prospective randomized control trial with two arms 'A' and 'B' that targeted 80-110 mg/dL and 140-180 mg/dL, respectively. This study was stopped because of excessive protocol violations. Patients in the 'A' arm only spent $39.5 \%$ of their time in the target range, and $8.7 \%$ experienced severe hypoglycemia $(\mathrm{BG}<40 \mathrm{mg} / \mathrm{dL})$. SPRINT [7] is an insulin-nutrition control protocol that achieved $54 \%$ of measurements in the $80-110 \mathrm{mg} / \mathrm{dL}$ range with a reduction in hypoglycemia compared to retrospective patients. STAR [25] is a new model-based insulin-nutrition control system currently in pilot trials with $63 \%$ of BG measurements in the $72-117 \mathrm{mg} / \mathrm{dL}$ range and reduced hypoglycemia.

Virtual trials offer the ability to design protocols in-silico by testing on virtual patients to optimize protocol performance and safety without risk to real patients. This system has been validated to reproduce the results of clinical trials on equivalent patient cohorts [27], and can be used to comprehensively evaluate the performance of any desired glucose control system. STAR and SPRINT used virtual trials to assess performance before clinical implementation. In contrast, UNC, Yale, and Glucontrol were first tested clinically.

This study used virtual patients to conduct a simulated clinical trial comparing the UNC, Yale, Glucontrol, SPRINT and STAR glucose control systems. The overall goal was to assess protocol safety and performance across different patient types, allowing aspects of safe, high performance protocols to be defined.

\section{METHODS}

\subsection{Virtual Patients and Simulation Environment}

Clinically validated virtual trials [27] were carried out using the SPRINT cohort clinical data [7] (371 patients, 39,841 hours, 26,646 measurements) to create virtual patients. Patient demographics are given in Table 1. The Upper South Regional Ethics Committee, New Zealand, granted ethics approval for the audit, analysis, and publication of this data. Virtual patients were generated from the hourly treatmentindependent insulin sensitivity profile of real patients [28] using the ICING model [30], allowing virtual trials to realistically simulate patient response to modified treatments administered by different protocols. This approach has been validated on independent matched cohort data [27] and in several clinical trials [25, 31-33].

Patients were considered to require glucose control once BG $>125 \mathrm{mg} / \mathrm{dL}$, and this value was used to determine the beginning of a virtual trial using the patient data. Interruptions in nutrition are common for some patients in clinical practice, and were incorporated by setting nutrition administration to zero over the same periods they occurred in the clinical data. Equally, parenteral nutrition was included in the simulations where it was given clinically.

\subsection{Control Protocols Comparison}

Five different protocols were assessed in simulation on this virtual cohort: STAR [25], SPRINT [7] and three other published protocols: UNC [22], Yale [23] and Glucontrol A [24]. STAR and SPRINT use IV insulin boluses, while the other 3 protocols deliver IV insulin infusions. All protocols take the form of dynamic sliding scales, apart from 
Table 1. Patient demographics

\begin{tabular}{ll}
\hline & SPRINT Cohort \\
\hline Total patients & 371 \\
Age (years) & $65[49-74]$ \\
Male (\%) & 63.6 \\
APACHE II score [29] & $18[15-24]$ \\
APACHE II risk of death $(\%)$ & $25.7[13.1-49.4]$ \\
Diabetes history & $62(16.7 \%)$
\end{tabular}

APACHE III Category

\begin{tabular}{lc}
\hline Operative & Number of patients \\
\hline Cardiovascular & $76(20 \%)$ \\
Respiratory & $9(2 \%)$ \\
Gastrointestinal & $60(16 \%)$ \\
Neurological & $7(2 \%)$ \\
Trauma & $14(4 \%)$ \\
Other (Renal, metabolic, orthopedic) & $4(1 \%)$ \\
\hline Non-Operative & Number of patients \\
\hline Cardiovascular & $39(11 \%)$ \\
Respiratory & $66(18 \%)$ \\
Gastrointestinal & $10(3 \%)$ \\
Neurological & $20(5 \%)$ \\
Trauma & $32(9 \%)$ \\
Sepsis (Renal, metabolic, orthopedic) & $17(5 \%)$
\end{tabular}

STAR (computerized stochastic forecasting). The rules for each protocol were programmed into the simulation software. Patients were divided into tertiles by their median within-patient model-based insulin sensitivity to divide the cohort by insulin resistance. To further group the patients by metabolic variability, they were divided into tertiles by their within-patient SI variability, defined as the normalized interquartile range (IQR) of SI. Results were analyzed in terms of safety, performance, and workload for each tertile:

- Hypoglycemia safety

- \%BG in severe hypoglycemic range (\%BG below $40 \mathrm{mg} / \mathrm{dL}$ )

- $\%$ BG in moderate hypoglycemic range ( $\%$ BG in the range of $40-60 \mathrm{mg} / \mathrm{dL}$ )

- Number of patients with BG in sever hypoglycemic range

- Number of patients with BG in moderate hypoglycemic range 
- $\quad$ Glucose control performance

$\circ \%$ BG within target range $(80-145 \mathrm{mg} / \mathrm{dL})$

- Hyperglycemic index. This quantifies the relative area of BG above a specific level [34], defined as $145 \mathrm{mg} / \mathrm{dL}$ in this study.

- Spread of BG (IQR)

- Glycemic lability index (GLI). GLI measures hour-to-hour changes in BG [35].

- Mean amplitude of glycemic excursions (MAGE). MAGE quantifies variability by calculating the relative size of $\mathrm{BG}$ decreases [36].

- Clinical workload

- Number of BG measurements per day

Clinical workload was evaluated using BG measurement frequency as a surrogate $[37,38]$, and $\mathrm{BG}$ data was resampled hourly to provide a consistent time-basis for comparison across protocols with different measurement and intervention intervals. Global insulin dosing behavior was investigated by isolating the insulin dose and relative change in insulin dose $( \pm 0.5 \mathrm{U})$ at glycemic levels between 40 and $145 \mathrm{mg} / \mathrm{dL}$.

Two-way ANOVA was used to compare the effect of protocol choice and patient category (by tertiles of SI or SI variability) on each aspect of performance.

\section{RESULTS}

Figure 1 presents results grouped by tertiles of median within-patient SI and indicate that high SI corresponds to the highest risk of hypoglycemia, and low SI corresponds to increased spread of glycemic levels and decreased performance. Of note, the incidence of severe hypoglycemia (BG $<40 \mathrm{mg} / \mathrm{dL}$ ) is relatively consistent across SI levels for the STAR, SPRINT and Yale protocols, but increases with SI for UNC and Glucontrol A. Glucose control performance is generally better in patients with higher SI. It is likely that this trend is caused by the ability to regulate glycemia with insulin doses below insulin effect saturation, which reduces performance for patients with very low SI. Statistical analysis indicates that protocol choice has a significant effect on hypoglycemia, but overall incidence of mild and severe hypoglycemia does not vary significantly between SI tertiles. Both protocol choice and SI tertile have a significant effect on performance and spread of BG.

Per-patient results in Table 2 present trends similar to Figure 1, with incidence of moderate hypoglycemia increasing with SI, and median hyperglycemic index significantly increased for patients with low SI. Wider spread of BG at low SI was supported by raised median GLI and MAGE scores, further suggesting increased BG variability.

Similarly, the results grouped by variability in SI as presented in Figure 2 and Table 3 show consistently increased hypoglycemia risk and decreased glucose control performance in patients with higher SI variability. In particular, Glucontrol showed 

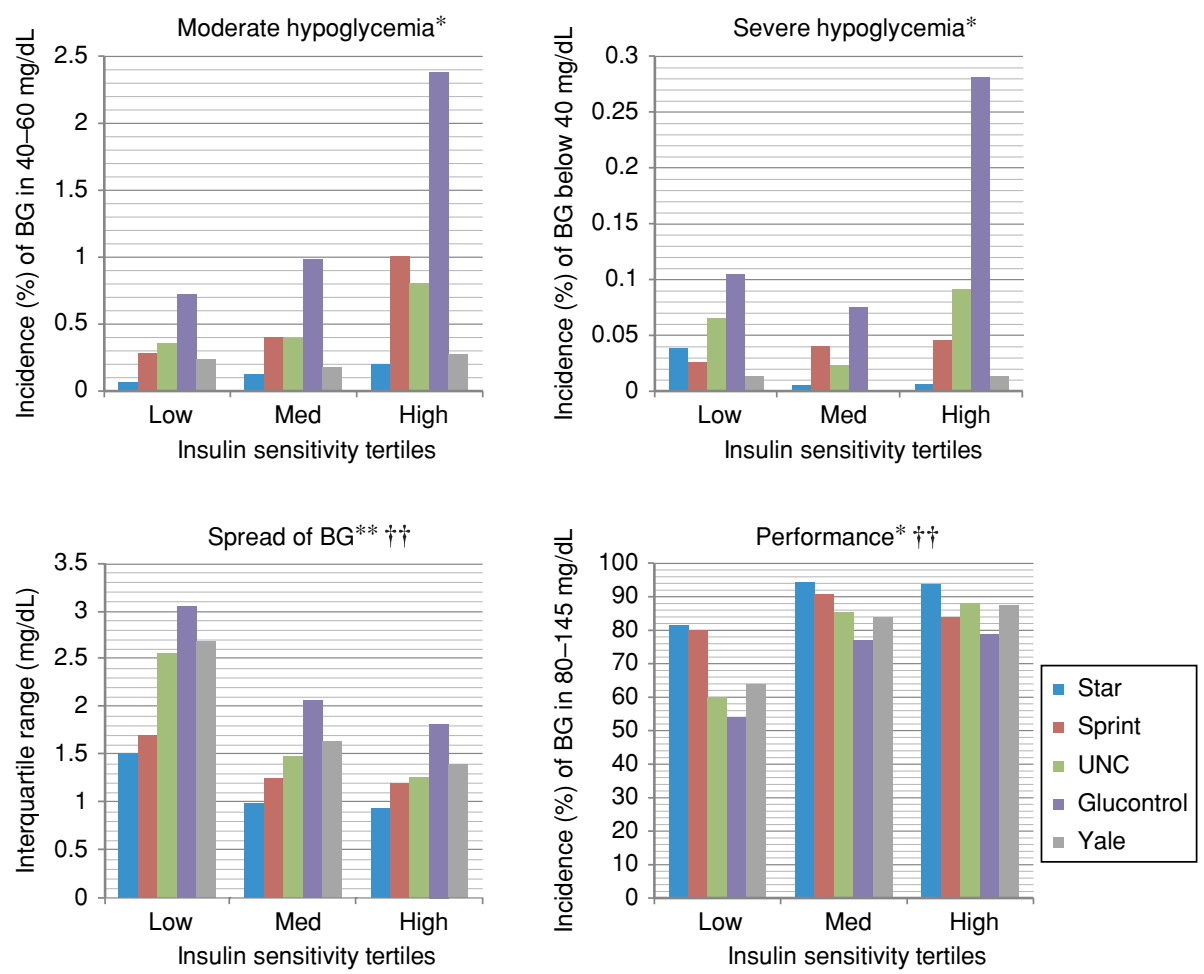

Figure 1. Hypoglycemia safety, BG variability, and glucose control performance metrics across assessed protocols grouped by insulin sensitivity level tertiles. Incidence of moderate hypoglycemia increased for all protocols for patients with higher sensitivity to insulin. Marked increases in severe hypoglycemia were evident with the Glucontrol A protocol. Variability of BG reduced and time in target ranges increased for patients with higher insulin sensitivity. Statistical significance of protocol choice was denoted by $*(\mathrm{p}<0.05)$ and $* *(\mathrm{p}<0.01)$, while statistical significance of different patient category tertiles was denoted by $\dagger(\mathrm{p}<0.05)$ and $\dagger \dagger(\mathrm{p}<0.01)$.

the highest incidence of severe hypoglycemia ( $>0.25 \%$ of the 26,646 BG measurements) for patients with high SI variability, whilst STAR and SPRINT which track SI were able to limit severe hypoglycemia to less than $0.07 \%$ across all insulin sensitivity and SI variability tertiles. Yale also showed extremely low hypoglycemia rates. Glucose control performance of each protocol deteriorated as patients' metabolic (SI) variability increased. Grouping patients by SI variability tertile also showed higher statistical significance than SI tertiles, across all performance and safety metrics. 
Table 2. Additional per-patient markers for performance and safety by insulin sensitivity tertile

\begin{tabular}{lccc}
\hline & \multicolumn{3}{c}{ Insulin Sensitivity Tertiles } \\
\cline { 2 - 4 } & Low & Med & High \\
\hline Hypoglycemia safety & & & \\
\hline Number of patients in & & & \\
$\quad 40-60$ mg/dL* $\dagger$ & & 23 & 32 \\
STAR & 22 & 69 & 154 \\
SPRINT & 27 & 68 & 122 \\
UNC & 55 & 169 & 364 \\
Glucontrol & 18 & 31 & 42 \\
Yale & & & \\
Number of patients & & 1 & 1 \\
$<40$ mg/dL* & 2 & 5 & 4 \\
STAR & 2 & 2 & 6 \\
SPRINT & 1 & 9 & 2 \\
UNC & 6 & 1 & \\
Glucontrol & 1 & & \\
Yale & & & \\
\hline
\end{tabular}

\section{Glucose control performance}

Median Hyperglycemic Index $[I Q R], \mathrm{mmol} / \mathrm{L} \dagger \dagger$

STAR

SPRINT

UNC

Glucontrol

Yale

$G L I[I Q R]$,

$$
m m o l^{2} \cdot h r^{-1} \cdot w k^{-1}+\dagger
$$

STAR

SPRINT

UNC

Glucontrol

Yale

MAGE [IQR],

$\mathrm{mmol} / \mathrm{L}^{* *}+\dagger$

STAR

SPRINT

UNC

Glucontrol

Yale

$\begin{array}{ccc}2.99[0.95-8.68] & 0.40[0.06-1.40] & 0.16[0.00-0.99] \\ 2.65[0.60-10.10] & 0.28[0.03-1.22] & 0.11[0.00-1.17] \\ 8.13[2.74-15.37] & 1.80[0.41-4.13] & 0.48[0.02-1.70] \\ 8.33[2.92-17.44] & 2.49[0.90-4.94] & 1.01[0.26-2.80] \\ 7.61[2.84-14.20] & 1.98[0.59-4.13] & 0.96[0.40-2.35]\end{array}$

$3.3[1.1-10.9]$

$0.7[0.3-2.6]$

$1.2[0.4-4.4]$

$0.9[0.4-3.8]$

$1.1[0.5-3.6]$

$1.6[0.6-5.6]$

$1.1[0.4-3.7]$

$1.5[0.5-5.3]$

$1.4[0.5-3.7]$

$1.4[0.7-4.2]$

$2.2[0.8-7.6]$

$1.87[1.48-2.48]$

1.99 [1.53-2.57]

$2.24[1.60-3.55]$

$1.95[1.48-2.51]$

$1.85[1.39-2.57]$

2.70 [2.04-3.91]

$2.12[1.61-2.73]$

$2.16[1.67-2.61]$

3.00 [2.30 - 4.80]

$2.80[1.96-3.81]$

2.93 [2.33 - 3.79]

2.95 [2.12-4.43]

2.29 [1.86-3.12] 

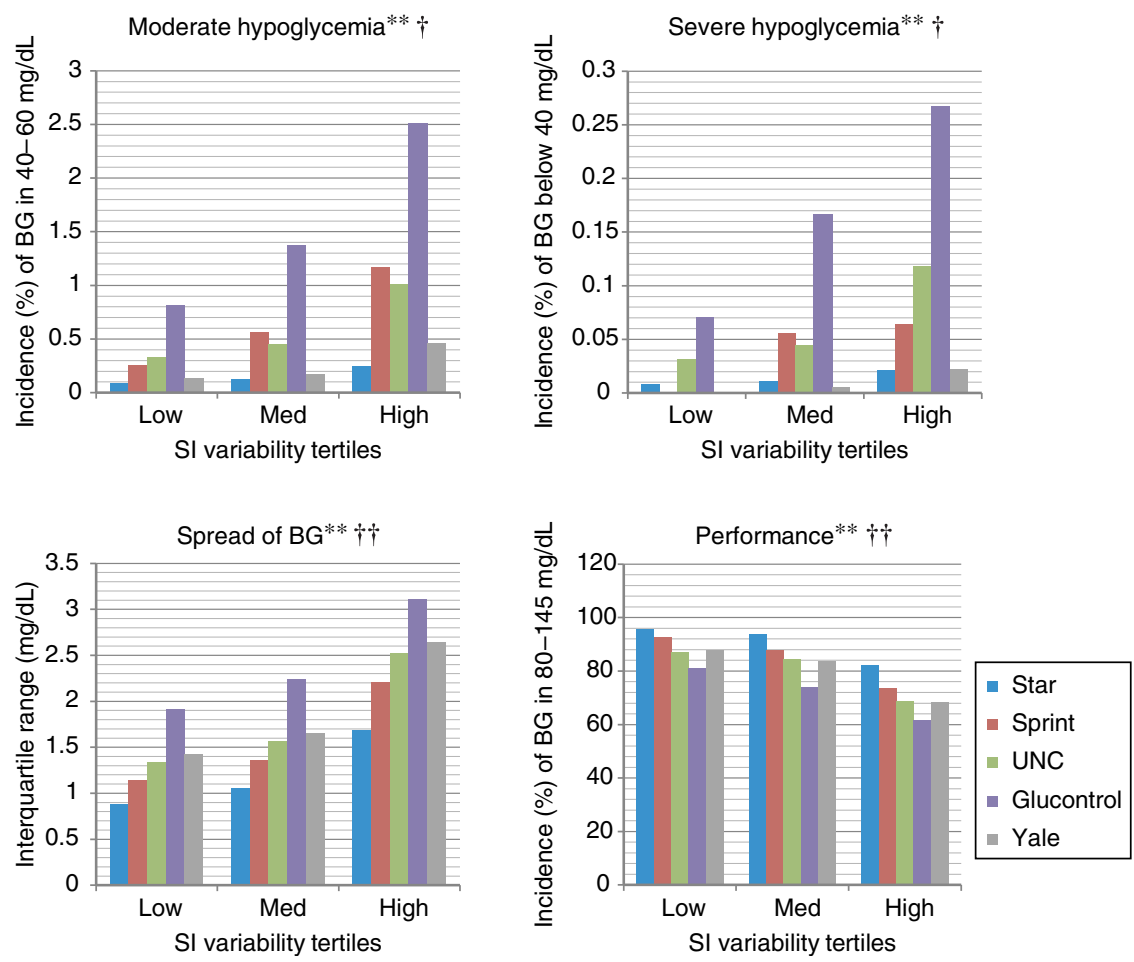

Figure 2. Hypoglycemia safety, BG variability, and glucose control performance metrics across assessed protocols grouped by insulin sensitivity variability tertiles. Highly variable patients tended to have a higher risk of hypoglycemia, particularly if treated with the Glucontrol A protocol. STAR and SPRINT contained severe hypoglycemia to less than $0.1 \%$ across patients. BG spread increased and glucose control performance decreased consistently with insulin sensitivity variability. Statistical significance of protocol choice was denoted by $*(\mathrm{p}<0.05)$ and $* *(\mathrm{p}<0.01)$, while statistical significance of different patient category tertiles was denoted by $\dagger(\mathrm{p}<0.05)$ and $\dagger \dagger(\mathrm{p}<0.01)$.

Figures 1 and 2 demonstrate that glucose control performance did not differ significantly between protocols across the range of SI (Figure 1) or SI variability (Figure 2). The key difference between protocols was the ability to maintain safety across each patient category. The highest incidence of mild and severe hypoglycemia for all protocols occurred under conditions of high SI and/or high SI variability. SPRINT, STAR and Yale were the least likely to cause severe hypoglycemia, limiting it to below $0.07 \%$ hourly BG. However, only STAR was able to consistently limit moderate hypoglycemia to below $0.3 \%$ hourly BG. In contrast, Glucontrol A caused more hypoglycemia than all the other protocols across each category. 
Table 3. Additional per-patient markers for performance and safety by SI variability tertile

\begin{tabular}{lccc}
\hline & \multicolumn{3}{c}{ SI Variability Tertiles } \\
\cline { 2 - 4 } & Low & Med & High \\
\hline Hypoglycemia safety & & & \\
\hline $\begin{array}{l}\text { Number of patients in } \\
\text { 40-60 mg/dL** } \dagger\end{array}$ & & & \\
STAR & 13 & 25 & 25 \\
SPRINT & 33 & 102 & 110 \\
UNC & 42 & 81 & 94 \\
Glucontrol & 105 & 248 & 235 \\
Yale & 17 & 31 & 43 \\
Number of patients & & & \\
$<40$ mg/dL** $\dagger$ & 1 & 1 & 2 \\
STAR & 0 & 6 & 5 \\
SPRINT & 2 & 2 & 5 \\
UNC & 6 & 15 & 13 \\
Glucontrol & 0 & 1 & 3 \\
Yale & & & \\
\hline
\end{tabular}

\section{Glucose control}

performance

Median Hyperglycemic

Index $[I Q R], \mathrm{mmol}^{*} \mathrm{~L}^{* *} \dagger$

$\begin{array}{lccc}\text { STAR } & 0.18[0.00-0.98] & 0.59[0.06-1.83] & 2.80[0.64-7.83] \\ \text { SPRINT } & 0.07[0.00-0.81] & 0.41[0.04-1.58] & 2.76[0.50-9.34] \\ \text { UNC } & 0.84[0.15-3.08] & 1.75[0.41-4.78] & 4.17[1.10-11.81] \\ \text { Glucontrol } & 1.38[0.52-3.64] & 2.50[0.80-5.60] & 4.25[1.75-13.17] \\ \quad \text { Yale } & 0.92[0.41-2.65] & 2.02[0.61-4.60] & 4.32[1.88-11.98] \\ \text { GLI }[I Q R], & & \\ \quad m m o l^{2} . h r^{-1} . w k^{-1} \dagger \dagger & & & \\ \text { STAR } & 0.9[0.3-4.3] & 0.9[0.3-3.0] & 2.7[0.9-8.5] \\ \text { SPRINT } & 1.4[0.5-6.4] & 1.3[0.4-4.8] & 5.8[1.6-20.1] \\ \text { UNC } & 1.2[0.5-4.7] & 1.2[0.4-3.4] & 3.4[1.2-9.9] \\ \text { Glucontrol } & 1.5[0.6-6.6] & 1.4[0.6-4.5] & 4.2[1.4-10.5] \\ \text { Yale } & 1.7[0.6-5.3] & 1.8[0.8-6.0] & 7.3[3.2-14.8] \\ \text { MAGE }[I Q R], & & & \\ \text { mmol/L** } \dagger \dagger & & & \\ \text { STAR } & & & \\ \text { SPRINT } & 1.62[1.36-2.23] & 1.95[1.58-2.49] & 2.50[1.86-3.56] \\ \text { UNC } & 1.72[1.30-2.16] & 1.86[1.46-2.55] & 2.55[1.88-3.58] \\ \text { Glucontrol } & 1.85[1.40-2.23] & 2.16[1.69-2.73] & 2.78[2.22-3.85] \\ \text { Yale } & 2.38[1.83-3.25] & 2.81[2.19-3.92] & 3.48[2.91-4.79] \\ & 1.94[1.63-2.37] & 2.29[1.90-3.33] & 3.30[2.51-4.33]\end{array}$



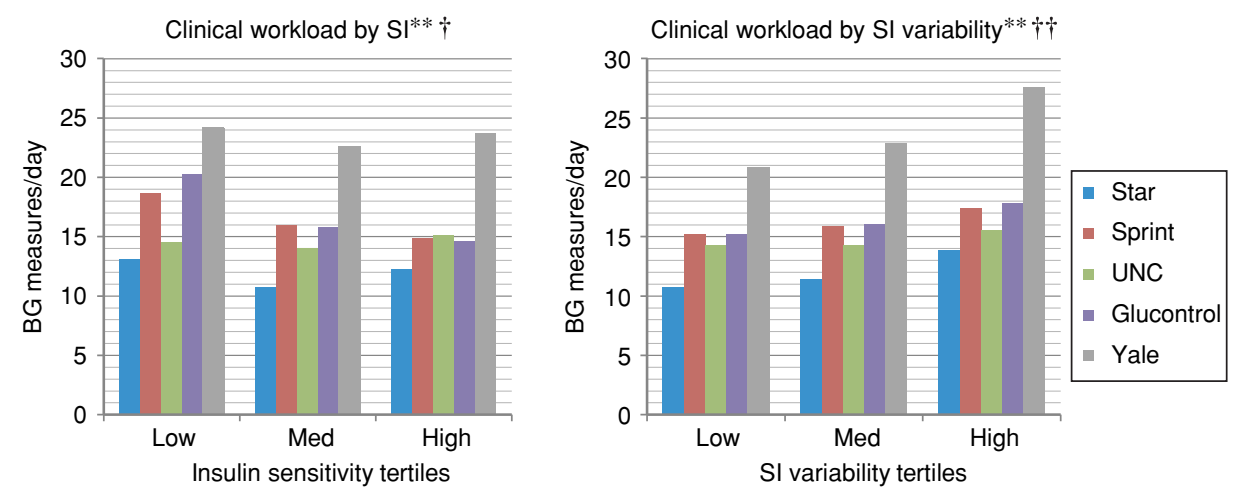

Figure 3. Clinical workload by patient category.

Figure 4 indicates that Glucontrol A demonstrates a limited ability to respond dynamically, with little change in insulin dose being a much more common response compared to similar protocols such as UNC. This behavior is particularly detrimental to patient safety for patients with high SI variability as shown in Figure 2, where Glucontrol A resulted in heightened severe hypoglycemia. STAR and SPRINT appear to be more dynamic insulin-dosing protocols, providing much greater variation in insulin doses in the displayed range. SPRINT was designed with a preference for moderate insulin levels, and this is clearly seen with the high incidence of $3 \mathrm{U}$ insulin dose selection in Figure 4.

Clinical workload by category (Figure 3 ) indicates similar behavior across protocols, with high SI variability or low SI corresponding to increased clinical workload, though UNC remains relatively consistent across both SI and SI variability tertiles. Finally, the clinical workload required by Yale was significantly higher than any of the other protocols, with high SI variability patients requiring more than 27 measures per day. Many of these extra measurements were triggered by the relatively conservative limits for hypoglycemia requiring intensive $\mathrm{BG}$ monitoring as per protocol and may
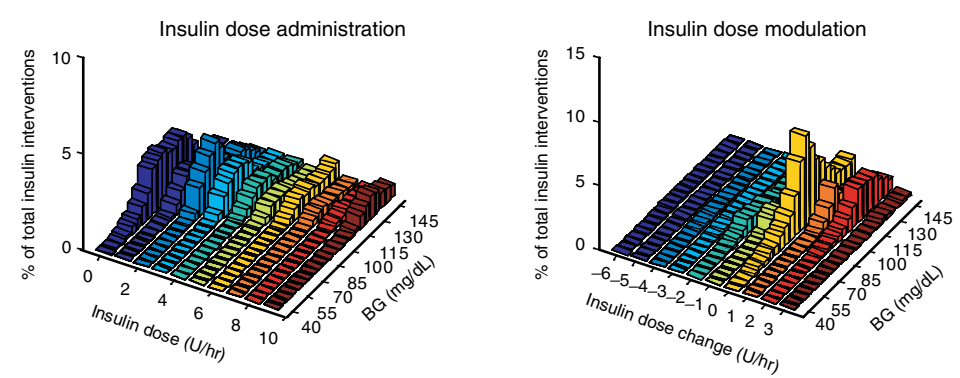

(a) STAR

Figure 4. (Continued) 

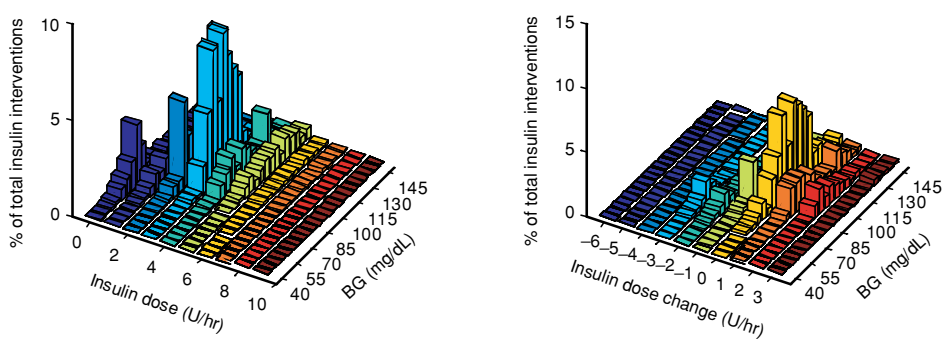

(b) SPRINT
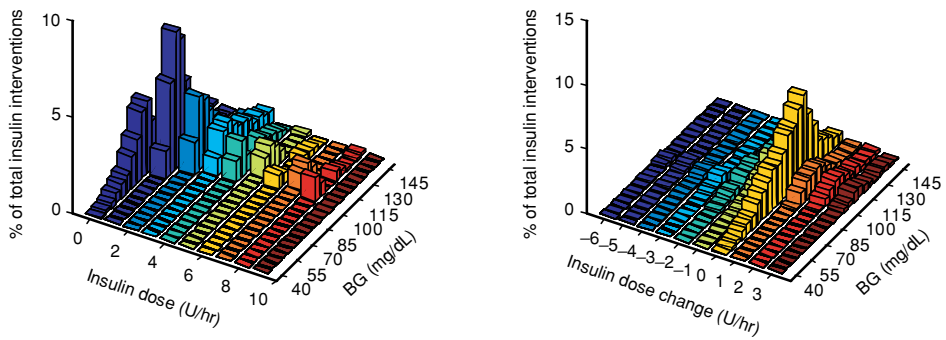

(c) UNC
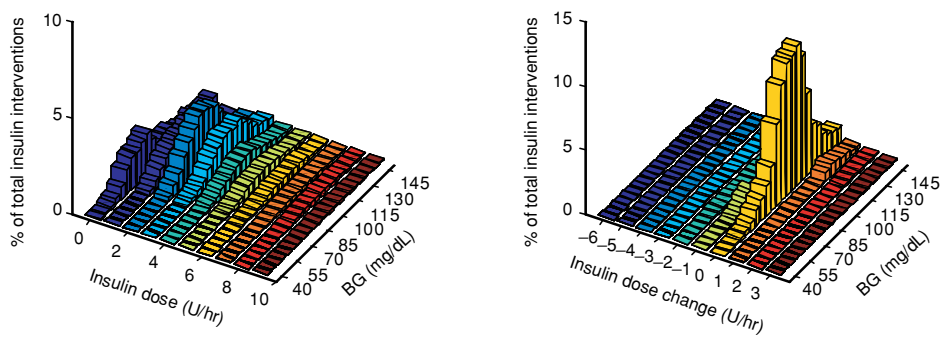

(d) Yale
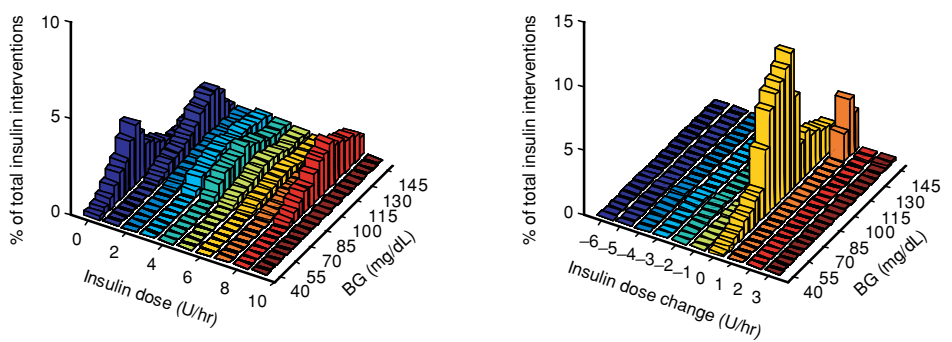

(e) Glucontrol

Figure 4. Insulin dosing at glycemic levels between 40 and $145 \mathrm{mg} / \mathrm{dL}$. Insulin dose administration plots the insulin rate chosen at each BG level during virtual trials, and insulin dose modulation shows the change in insulin dose. UNC modulates insulin the most from the insulin-only protocols, whereas Glucontrol uses relatively high rates of insulin with little adjustment of the rate. STAR and SPRINT also modulate nutrition in addition to insulin. 
potentially be a source of non-compliance in clinical practice. Thus, Yale performance comes at a cost in workload compared to SPRINT and STAR which achieve performance via their adaptive tracking of SI.

\section{DISCUSSION}

High SI and high SI variability were clearly identified as the major factors discriminating the degree of safety between glucose control protocols. The trends in Figures 1-3 suggest that to provide protection from moderate and severe hypoglycemia across a wide range of patient types, a clinically applied protocol must be able to recognize and respond to patients with high SI and large changes in patient condition. The comparison between STAR (a highly dynamic, computerized, risk-based framework that directly identifies SI) and Glucontrol A (a relatively static tabular protocol, responding to changes in BG) illustrates the two extremes, indicated by both insulin dosing behavior and glycemic outcome. Yale, SPRINT, and UNC demonstrate the suitability of a tabular protocol, with the benefits of SPRINT over UNC, likely due to SPRINT's design aiming to directly identify the underlying SI changes that lead to a BG response. Additionally, SPRINT and STAR modulate nutrition in addition to insulin as a means to obtain a stronger, more dynamic glycemic response without increasing the risk due to changes in SI and insulin effect saturation at high doses.

Clinical trial simulation using virtual patients is a valuable tool to analyze and characterize performance of glucose control protocols. In particular, it can be employed to identify areas of weakness in a protocol design that would otherwise only appear after detrimental clinical incidents in real patients. The tabular form of the UNC, Yale and Glucontrol A protocols makes it difficult to assess how they will perform from simply reading the protocols. Virtual trials directly communicate the expected performance and implementation issues implicit in each system, and validation ensures that the results are representative of likely clinical outcomes over specific BG ranges and nutrition/insulin inputs.

Virtual patients can also be used directly for protocol design, as performed with SPRINT [39] and STAR [25]. Designing a glucose control protocol for clinical implementation requires balancing clinical workload, performance, and safety. Being able to quantify each trade-off is a powerful tool, and simulation allows for investigation of possible effects without placing patients at risk. Protecting the patient at each step of the process is an important concern, particularly after the discouraging outcomes of several protocol trials that resulted in increased hypoglycemia [2].

Compliance in the clinical unit with a specified glucose control protocol plays a major role in the success of a clinical trial. The Glucontrol study was stopped early due to excessive protocol violations [24], and subsequent analysis indicated that BG measurement frequency was often not compliant with protocol instructions [27]. The rate of change of insulin dosage in the Glucontrol protocol depends upon BG measurement frequency by design, thus altering the rate of BG measurement will alter control response and subsequently protocol dynamics, directly affecting safety and performance. Optimizing BG measurement frequency requires balancing improved performance and safety with increased nursing workload, and thus requires further analysis. 
The Yale protocol showed high BG measurement rate, up to 53\% higher than other protocols and often triggered by the relatively conservative threshold for intensive BG monitoring around hypoglycemic events. It is possible that nurses will override protocol rules and measure BG less frequently to match typical clinical practice [37]. These changes too may directly impact safety as they occur at lower BG levels.

Finally, protocols such as Yale and UNC could recommend relatively high insulin rates of up to 10-30 U/hr, which may also be capped or curtailed if applied clinically. Simulations will perform protocols as instructed and in these analyses, such noncompliance issues were not implemented, although they may be readily added. However, whenever non-compliance occurs, it triggers deviations from intended safe, effective performance, and thus these situations should be avoided by design.

Utilizing simulations over clinical trials isolates the development process from application on patients in a clinical setting. Virtual trials can easily be extended to investigate factors such as the influences of nutrition on glucose control, methods of insulin delivery, and differences in clinical practices between units that may provide safety or performance benefits or insights that would not otherwise be realized without large-scale clinical trials. Virtual trials are limited to applications where sufficient clinical data have been gathered, and a suitable treatment-independent parameter such as SI must exist. Validity of this approach for glycemic control has previously been established by Chase et al. [27]. Use of a non-linear model, coupled with an adaptive control system and a data-driven stochastic forecasting approach such as STAR, introduces a level of complexity that means trade-offs between factors such as performance and safety can only be adequately and safely explored through virtual trials.

\section{CONCLUSIONS}

Achieving accurate glycemic control in intensive care patients has proven difficult in practice. Performance of systems from a variety of institutes resulted in a variety of clinical outcomes, likely due to the different ability of each protocol to cope with highly insulin sensitive and/or variable patients. Virtual trials can be used to investigate why some protocols impacted on patient safety from hypoglycemia. In particular, increases in hypoglycemia were observed for protocols that failed to respond dynamically to changing patient condition. Identifying such areas of concern highlights how virtual patients and simulated trials protocols can be used to investigate and refine clinical practice long before patient lives hinge on the outcomes.

\section{CONFLICT OF INTEREST:}

The authors indicated no potential conflicts of interest.

\section{NOMENCLATURE}

APACHE Acute Physiology and Chronic Health Evaluation

BG Blood glucose concentration, $\mathrm{mg} / \mathrm{dL}$

GLI Glycemic lability index, $\mathrm{mmol}^{2} \cdot \mathrm{hr}^{-1} \cdot \mathrm{wk}^{-1}$

IQR Interquartile range, $\mathrm{mg} / \mathrm{dL}$

MAGE Mean amplitude of glycemic excursions, mmol/L 
SI Insulin sensitivity

SPRINT Specialized Relative Insulin and Nutrition Tables

STAR Stochastic TARgeted

UNC University of North Carolina

\section{REFERENCES}

[1] Krinsley, JS. Association between hyperglycemia and increased hospital mortality in a heterogeneous population of critically ill patients. Mayo Clin Proc. 2003, 78: 1471-1478.

[2] Griesdale, DE, de Souza, RJ, van Dam, RM, Heyland, DK, Cook, DJ, Malhotra, A, Dhaliwal, R, Henderson, WR, Chittock, DR, Finfer, S, and Talmor, D. Intensive insulin therapy and mortality among critically ill patients: a meta-analysis including NICE-SUGAR study data. CMAJ. 2009, 180: 821-827.

[3] Bagshaw, S, Bellomo, R, Jacka, M, Egi, M, Hart, G, George, C, and Committee, tACM. The impact of early hypoglycemia and blood glucose variability on outcome in critical illness. Critical Care. 2009, 13: R91.

[4] Egi, M, Bellomo, R, Stachowski, E, French, CJ, and Hart, G. Variability of blood glucose concentration and short-term mortality in critically ill patients. Anesthesiology. 2006, 105: 244-252.

[5] Krinsley, JS. Glycemic variability: a strong independent predictor of mortality in critically ill patients. Crit Care Med. 2008, 36: 3008-3013.

[6] Van den Berghe, G, Wouters, PJ, Bouillon, R, Weekers, F, Verwaest, C, Schetz, M, Vlasselaers, D, Ferdinande, P, and Lauwers, P. Outcome benefit of intensive insulin therapy in the critically ill: Insulin dose versus glycemic control. Crit Care Med. 2003, 31: 359-366.

[7] Chase, JG, Shaw, G, Le Compte, A, Lonergan, T, Willacy, M, Wong, X-W, Lin, J, Lotz, T, Lee, D, and Hann, C. Implementation and evaluation of the SPRINT protocol for tight glycaemic control in critically ill patients: a clinical practice change. Critical Care. 2008, 12: R49.

[8] Krinsley, JS. Effect of an intensive glucose management protocol on the mortality of critically ill adult patients. Mayo Clin Proc. 2004, 79: 992-1000.

[9] Chase, JG, Pretty, CG, Pfeifer, L, Shaw, GM, Preiser, JC, Le Compte, AJ, Lin, J, Hewett, D, Moorhead, KT, and Desaive, T. Organ failure and tight glycemic control in the SPRINT study. Crit Care. 2010, 14: R154.

[10] Krinsley, JS and Jones, RL. Cost analysis of intensive glycemic control in critically ill adult patients. Chest. 2006, 129: 644-650.

[11] Van den Berghe, G, Wouters, PJ, Kesteloot, K, and Hilleman, DE. Analysis of healthcare resource utilization with intensive insulin therapy in critically ill patients. Crit Care Med. 2006, 34: 612-616.

[12] Wiener, RS, Wiener, DC, and Larson, RJ. Benefits and risks of tight glucose control in critically ill adults: a meta-analysis. JAMA. 2008, 300: 933-944.

[13] Moghissi, ES, Korytkowski, MT, DiNardo, M, Einhorn, D, Hellman, R, Hirsch, IB, Inzucchi, SE, Ismail-Beigi, F, Kirkman, MS, and Umpierrez, GE. American Association of Clinical Endocrinologists and American Diabetes Association consensus statement on inpatient glycemic control. Diabetes Care. 2009, 32: 1119-1131.

[14] Lin, J, Lee, D, Chase, J, Hann, C, Lotz, T, and Wong, X. Stochastic Modelling of Insulin Sensitivity Variability in Critical Care. Biomedical Signal Processing \& Control. 2006, 1: 229-242.

[15] Van den Berghe, G, Wilmer, A, Hermans, G, Meersseman, W, Wouters, PJ, Milants, I, Van Wijngaerden, E, Bobbaers, H, and Bouillon, R. Intensive insulin therapy in the medical ICU. N Engl J Med. 2006, 354: 449-461.

[16] Van den Berghe, G, Wouters, P, Weekers, F, Verwaest, C, Bruyninckx, F, Schetz, M, Vlasselaers, D, Ferdinande, P, Lauwers, $\mathrm{P}$, and Bouillon, R. Intensive insulin therapy in the critically ill patients. $N$ Engl J Med. 2001, 345: 1359-1367. 
[17] Le Compte, AJ, Pretty, CG, Lin, J, Shaw, GM, Lynn, A, and Chase, JG. Impact of variation in patient response on model-based control of glycaemia in critically ill patients. Comput Methods Programs Biomed. 2011

[18] Black, PR, Brooks, DC, Bessey, PQ, Wolfe, RR, and Wilmore, DW. Mechanisms of insulin resistance following injury. Ann Surg. 1982, 196: 420-435.

[19] Suhaimi, F, Le Compte, A, Preiser, JC, Shaw, GM, Massion, P, Radermecker, R, Pretty, CG, Lin, J, Desaive, T, and Chase, JG. What makes tight glycemic control tight? The impact of variability and nutrition in two clinical studies. J Diabetes Sci Technol. 2010, 4: 284-298.

[20] Le Compte, A, Chase, JG, Lynn, A, Hann, C, Shaw, G, Wong, X-W, and Lin, J. Blood Glucose Controller for Neonatal Intensive Care: Virtual Trials Development and First Clinical Trials. Journal of Diabetes Science and Technology. 2009, 3: 1066-1081.

[21] Korsatko, S, Ellmerer, M, Schaupp, L, Mader, JK, Smolle, KH, Tiran, B, and Plank, J. Hypoglycaemic coma due to falsely high point-of-care glucose measurements in an ICU-patient with peritoneal dialysis: a critical incidence report. Intensive Care Med. 2009, 35: 571-572.

[22] Braithwaite, SS, Edkins, R, Macgregor, KL, Sredzienski, ES, Houston, M, Zarzaur, B, Rich, PB, Benedetto, B, and Rutherford, EJ. Performance of a dose-defining insulin infusion protocol among trauma service intensive care unit admissions. Diabetes Technol Ther. 2006, 8: 476-488.

[23] Goldberg, PA, Roussel, MG, and Inzucchi, SE. Clinical Results of an Updated Insulin Infusion Protocol in Critically Ill Patients. Diabetes Spectrum. 2005, 18: 188-191.

[24] Preiser, JC, Devos, P, Ruiz-Santana, S, Melot, C, Annane, D, Groeneveld, J, Iapichino, G, Leverve, X, Nitenberg, G, Singer, P, Wernerman, J, Joannidis, M, Stecher, A, and Chiolero, R. A prospective randomised multi-centre controlled trial on tight glucose control by intensive insulin therapy in adult intensive care units: the Glucontrol study. Intensive Care Med. 2009, 35: 1738-1748.

[25] Evans, A, Shaw, GM, Le Compte, A, Tan, CS, Ward, L, Steel, J, Pretty, CG, Pfeifer, L, Penning, S, Suhaimi, F, Signal, M, Desaive, T, and Chase, JG. Pilot proof of concept clinical trials of Stochastic Targeted (STAR) glycemic control. Ann Intensive Care. 2011, 1: 38.

[26] Hovorka, R, Kremen, J, Blaha, J, Matias, M, Anderlova, K, Bosanska, L, Roubicek, T, Wilinska, ME, Chassin, LJ, Svacina, S, and Haluzik, M. Blood Glucose Control by a Model Predictive Control Algorithm with Variable Sampling Rate Versus a Routine Glucose Management Protocol in Cardiac Surgery Patients: A Randomized Controlled Trial. J Clin Endocrinol Metab. 2007, 92: 2960-2964.

[27] Chase, JG, Suhaimi, F, Penning, S, Preiser, JC, Le Compte, AJ, Lin, J, Pretty, CG, Shaw, GM, Moorhead, KT, and Desaive, T. Validation of a model-based virtual trials method for tight glycemic control in intensive care. Biomed Eng Online. 2010, 9: 84.

[28] Hann, CE, Chase, JG, Lin, J, Lotz, T, Doran, CV, and Shaw, GM. Integral-based parameter identification for long-term dynamic verification of a glucose-insulin system model. Comput Methods Programs Biomed, 2005. 77: 259-270.

[29] Knaus, WA, Draper, EA, Wagner, DP, and Zimmerman, JE. APACHE II: a severity of disease classification system. Crit Care Med. 1985, 13: 818-829.

[30] Lin, J, Razak, NN, Pretty, CG, Le Compte, A, Docherty, P, Parente, JD, Shaw, GM, Hann, CE, and Geoffrey Chase, J. A physiological Intensive Control Insulin-Nutrition-Glucose (ICING) model validated in critically ill patients. Comput Methods Programs Biomed. 2011, 102: 192-205.

[31] Penning, S, Le Compte, AJ, Moorhead, KT, Desaive, T, Massion, P, Preiser, JC, Shaw, GM, and Chase, JG. First pilot trial of the STAR-Liege protocol for tight glycemic control in critically ill patients. Comput Methods Programs Biomed. 2011

[32] Wong, XW, Singh-Levett, I, Hollingsworth, LJ, Shaw, GM, Hann, CE, Lotz, T, Lin, J, Wong, OS, and Chase, JG. A novel, model-based insulin and nutrition delivery controller for glycemic regulation in critically ill patients. Diabetes Technol Ther, 2006, 8: 174-190.

[33] Chase, JG, Shaw, GM, Lin, J, Doran, CV, Hann, C, Lotz, T, Wake, GC, and Broughton, B. Targeted glycemic reduction in critical care using closed-loop control. Diabetes Technol Ther. 2005, 7: 274-282. 
[34] Vogelzang, M, Horst, ICvd, and Nijsten, MW. Hyperglycaemic Index as a Tool to Assess Glucose Control: A Retrospective Study. Crit Care. 2004, 8: R122-R127.

[35] Ryan, EA, Shandro, T, Green, K, Paty, BW, Senior, PA, Bigam, D, Shapiro, AM, and Vantyghem, MC. Assessment of the severity of hypoglycemia and glycemic lability in type 1 diabetic subjects undergoing islet transplantation. Diabetes. 2004, 53: 955-962.

[36] Service, FJ, Molnar, GD, Rosevear, JW, Ackerman, E, Gatewood, LC, and Taylor, WF. Mean amplitude of glycemic excursions, a measure of diabetic instability. Diabetes. 1970, 19: 644-655.

[37] Aragon, D. Evaluation of nursing work effort and perceptions about blood glucose testing in tight glycemic control. Am J Crit Care, 2006. 15: 370-377.

[38] Mackenzie, I, Ingle, S, Zaidi, S, and Buczaski, S. Tight glycaemic control: a survey of intensive care practice in large English hospitals. Intensive Care Med. 2005, 31: 1136.

[39] Lonergan, T, LeCompte, A, Willacy, M, Chase, JG, Shaw, GM, Wong, XW, Lotz, T, Lin, J, and Hann, CE. A simple insulin-nutrition protocol for tight glycemic control in critical illness: development and protocol comparison. Diabetes Technol Ther. 2006, 8: 191-206. 


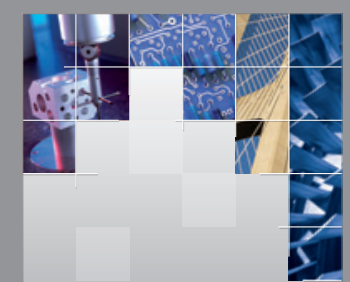

\section{Enfincering}
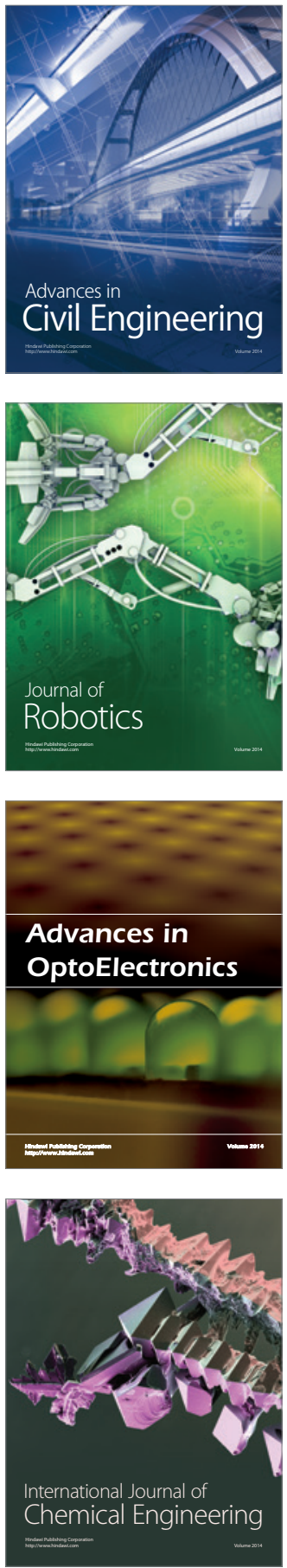

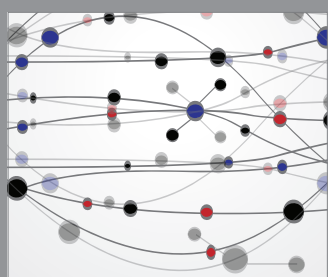

The Scientific World Journal

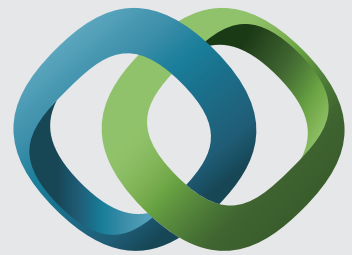

\section{Hindawi}

Submit your manuscripts at

http://www.hindawi.com
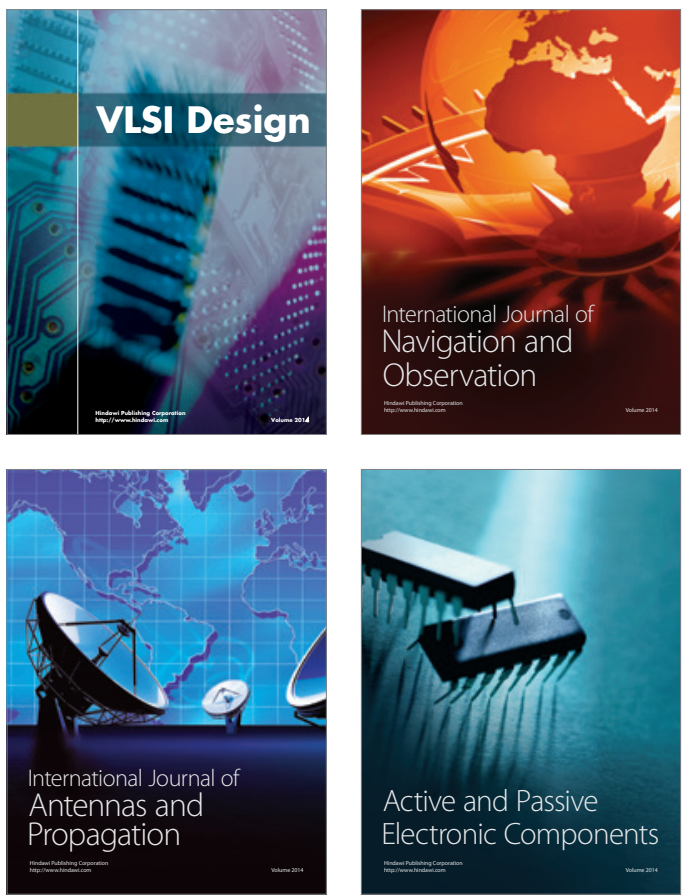
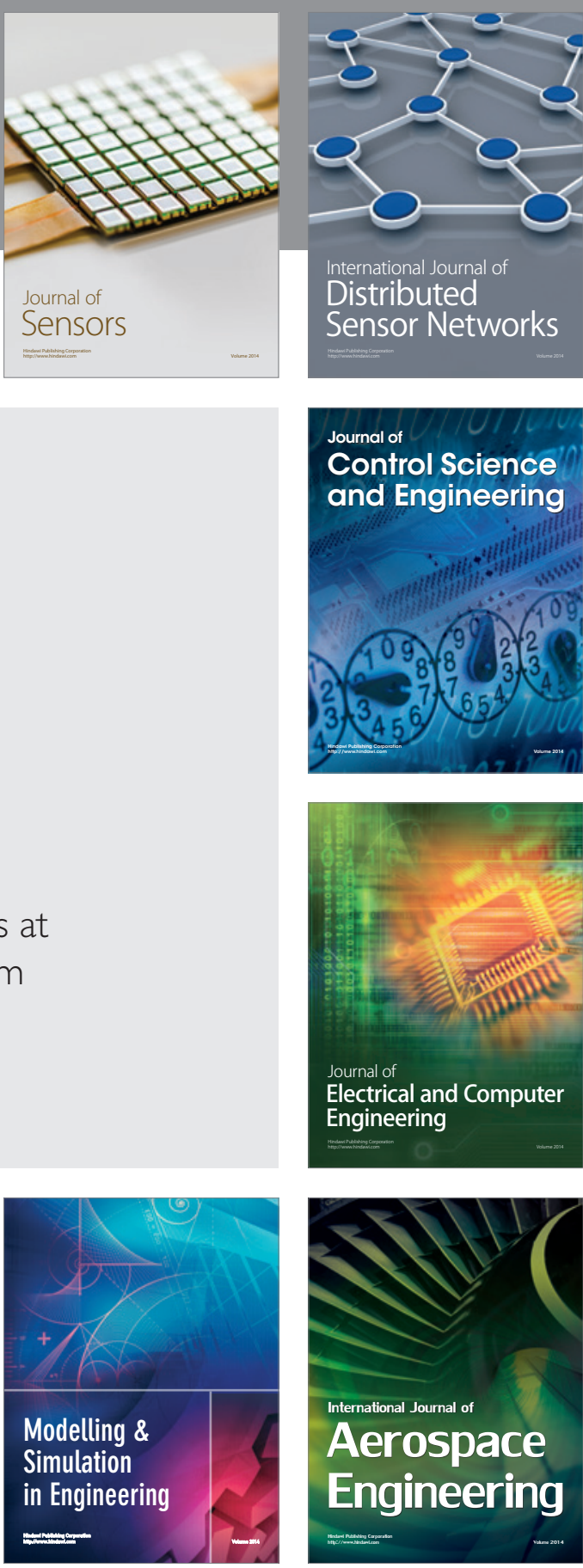

International Journal of

Distributed

Sensor Networks

Journal of

Control Science

and Engineering
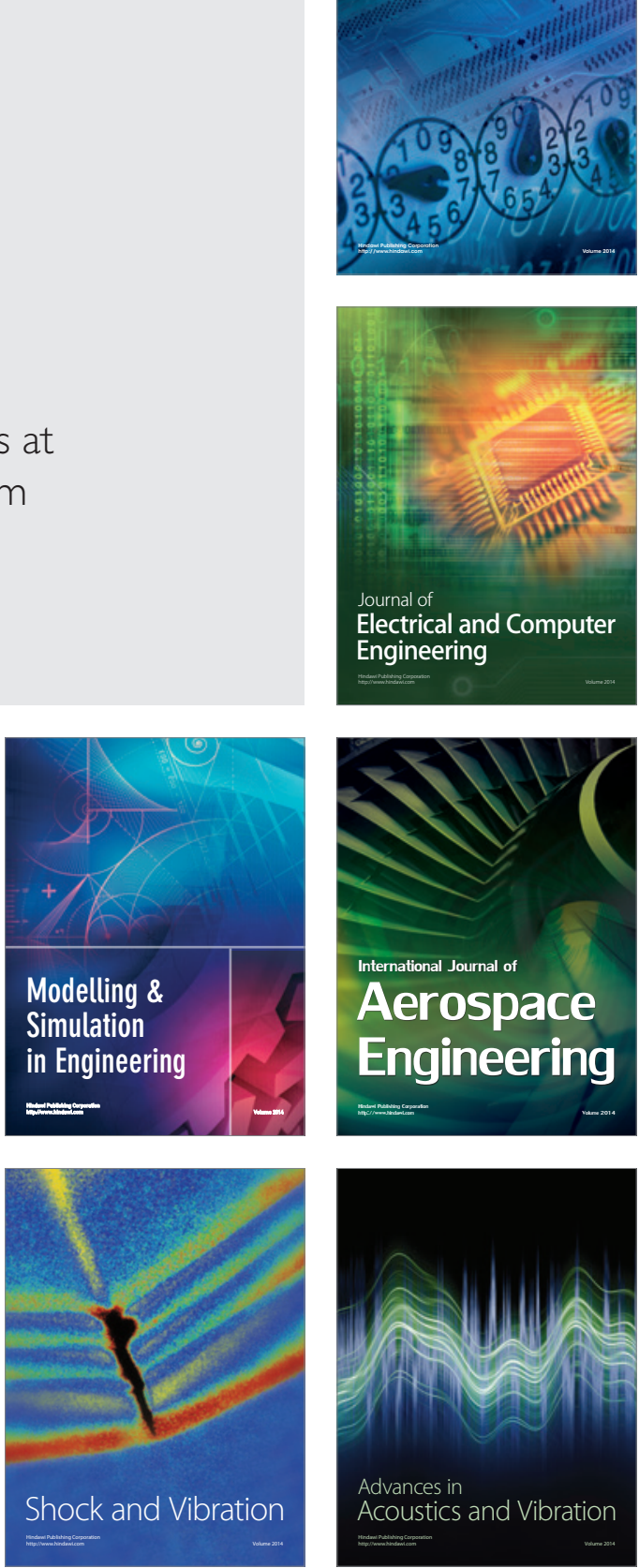